\title{
An Analysis of Ecological English-Major Teaching Mode in MOOCs
}

\author{
Qian JIANG
}

English Department, Wuhan University of Technology Huaxia College, Wuhan, 430223, China

email: jiangqian@hust.edu.cn

Key Words: English-major teaching, Ecological prospective, MOOCs

\begin{abstract}
A digital tsunami stirred by MOOCs threatens to sweep aside conventional university education. The research, from the ecological perspective aims to prove the inevitable combination of MOOCs and ecological mode in English-major teaching, and then points out the profound changes of the main four ecological elements in English-major teaching after MOOCs get involved. Through comparison and analysis, the paper gives suggestions on developing ecological English-major teaching mode in MOOCs from four aspects.
\end{abstract}

\section{Introduction}

Education ecology was initially posed by Dean Cremin L.A from Teachers College, Columbia University in 1976. [1]As the result of penetration between education and ecology, it discusses the features and functions of education ecology in order to find out basic education rules and better methods to optimize teaching and learning. Einar Haugen mentioned in a report, "the relationship between language itself and its surroundings is just a kind of ecological connection between living beings with their survival environment." Since then language ecology, the metaphor has been widely used, which is defined as a systematic, integral, coordinate and dynamic language teaching and research mode, examining the interaction among students, teachers, language and environment and their impacts upon language acquisition from different aspects.

Our traditional English-major teaching is one-sided and lacking in ecological prosperity. Someone may only concern about the language itself and be restricted by pure objectivity, ignoring participants' subjectivity; someone may just focus on external factors, over-valuing their dominating power and over-looking language and students. These drawbacks can be overcome by importing MOOCs. This paper proposes to examine a series of chain reaction brought by MOOCs in English-major teaching ecosystem: teachers' traditional status and functions are greatly weakened; students' learning style and condition are improved a lot; English, the language's connotation and denotation are activated instantly; Environment is endowed with incomparable flexibility and availability to the public. By analyzing and comparing, this paper aims to give suggestions on developing ecological English-major teaching model in MOOCs from four aspects, and help improve the English-major teaching into a new era.

\section{Inevitable combinations of MOOCs and ecological teaching}

In 1998, Foreign Language Teaching in Colleges and Universities Steering Committee released "Advice on foreign language majors of undergraduate education reform in the 21st century" which pointed out the five problems urgent to be solved in language teaching. Decades past, the problems still exist, such as unsystematic teaching materials, deficient teaching resources, backward teaching methods and irrational teaching content, etc. [2]In 2011,professor Weidong Dai pointed out in his paper that the most prominent problems in China's English education is dumb English learning and inefficient English teaching.

The above dilemma stimulates us to re-examine each element in English teaching and learning from the ecological prospective. The re-evaluation upon students, teachers, language and environment is highlighted. These four ecological elements, interacting and influencing each other, form a neo-mode which features balance between integrity and dynamic, co-existence of variety 
and peculiarity, reciprocity between openness and interaction, and complementation between distinction and standard. This ecological English-major teaching mode aims to develop each elements harmoniously and to help improve English-major teaching.

Meanwhile, MOOC (Massive Open Online Course) provides new solutions to English teaching, which presents a complete online teaching scheme, including teachers, learners, videos, assignment, forum interaction, email communication and exams. MOOCs enjoy abundant excellent teaching materials, sharing teaching videos from top universities in the world. Such novel and authoritative videos can guarantee both teachers and students to enrich their English knowledge and improve efficiency. In addition, MOOCs successfully break the barriers of time, location and cost in traditional teaching, its variety and individuality facilitating students' self-cultivation.

Table 1: the combination of MOOCs and English-major ecosystem

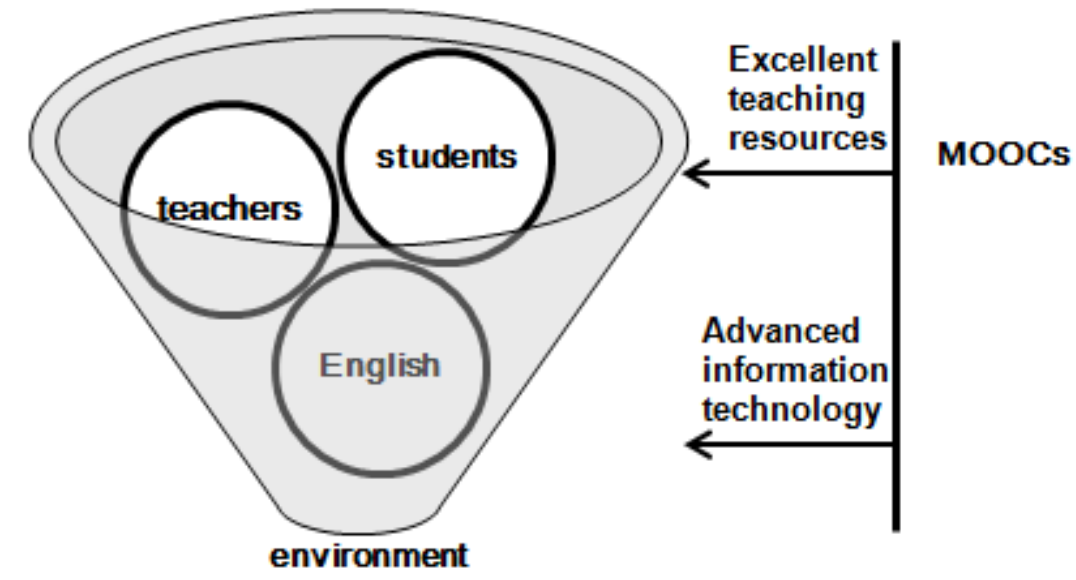

In table 1, environment is the teaching field for the other three elements, and each of these four closely interacts in the ecosystem, which is bridged with MOOCs by their main two merits. The ecological English-major teaching mode is not fixed, whose dynamics and openness are overlapped with MOOCs. Their marriage, not by chance, it is a must tendency for English-major teaching. In the tide of MOOCs, English-major teaching should keep pace with time, make great efforts to establish harmonious and beneficiary relationship among different ecological elements, and find out the best methods to optimize teaching and learning.

\section{Profound changes of Ecological elements in MOOCs}

Teachers, the main body of teaching

Teachers are endowed with new statues and functions. In traditional education, teachers dominate and order students to obey them in a parental style. However, the ecological teaching requires teachers to naturally influence students by their own academic expertise, personal charisma, profound knowledge and broad mind, not by any system or power. Equal to teachers, students are encouraged to speak more and participate more in teaching. MOOCs also put forward higher requests to the teachers that they should closely combine students' self study before class with the in-class teaching activity.[3] In MOOCs, teachers are no longer the sage on the stage but the guide on the side, not only the performers but also learners. They can learn the excellent teaching materials in MOOCs to improve their expertise and acquire professional knowledge on information and English-related courses through whole life. Teachers' status change can be clearly displayed in table 2 as followed. 
Table 2: status change of teachers

\begin{tabular}{c|c} 
Traditional mode & Ecological mode in MOOCS \\
\hline lecturer & lecturer \& learner \\
\hline english teacher & $\begin{array}{c}\text { expert on English \& } \\
\text { information technology }\end{array}$ \\
\hline performer & director \\
\hline sage & guider \\
\hline dictator & democrat
\end{tabular}

Students, the main body of learning

Students' core position has been further strengthened. Traditional teaching neglects students' cognitive status, so it is difficult to develop their creative thinking and learning initiative. However, the ecological teaching attaches more importance to students' cognitive status, from the following aspects: 1. teaching purposes, content and levels should be clear to students; 2 . Students' intention in teaching activities should be respected; 3. teaching methods and teaching language should be acceptable and attractive to students. Obviously, students are regarded as the basic to support the whole teaching ecosystem. [4]MOOCs provide flamboyant technology to support it with refined materials full of wise thoughts and modern sense close to real life, which can greatly arouse students' enthusiasm to learn. Beside, the fancy and stylish MOOCs can help students to get the information more and better by the acoustic and visual stimulus.

Table 3: Students' satisfaction in MOOCs
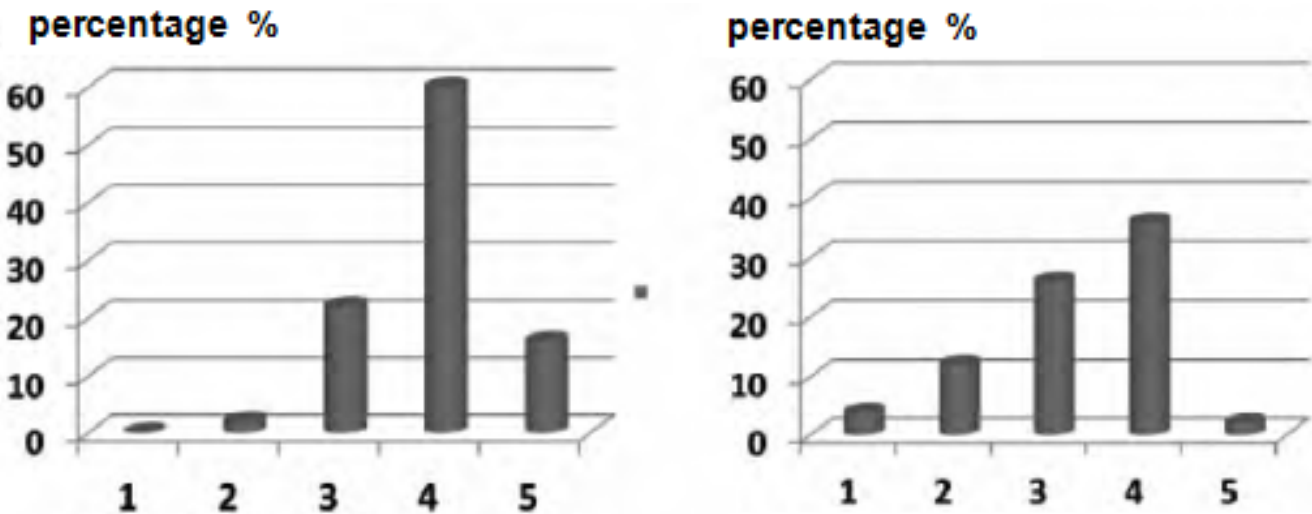

students' satisfaction on teaching design students' satisfication on learning effect

[5]In table 3, data acquisition, based on Likert rating scale (1.strongly disagree, 2.disagree, 3.neither agree nor disagree, 4.agree, 5.strongly agree) is studied upon 1050 students to conclude that most students give positive feedback to MOOCs. The result shows: students' satisfaction on teaching design is up to $74.5 \%($ Mean=3.86, $\mathrm{SD}=0.677$ ), and their satisfaction on learning effect is $36.7 \%($ Mean=3.18, $\mathrm{SD}=0.834)$.

English, the teaching material

Ecological teaching in MOOCs has expanded connotation and denotation. Traditional teaching espouses that language acquisition is conducted in a shattered and non-ecological way. Teachers cut the passage into fragmental units, like words, sentences and grammar points, and grammar acquisition is highly stressed while the ability of listening and speaking is neglected. Ecological English-major teaching denies such one-sided mode, and puts English in a wilder ecosystem to expand its connotation and denotation, which includes the comparative study between English and Chinese, English world culture education based on Chinese traditional culture, thorough study on language and skill. MOOCs make such process interesting and efficient. Queen's English is wildly used, which is beneficial to improve students' ability of listening and speaking; its various and up-to-date content and display are ear-catching and eye-catching to keep students' study passion; its globalized practice makes western culture, society and values more accessible to students.

3.4 Environment, the teaching field 
The teaching field is beyond its traditional geographic concept in MOOCs, which enjoys more flexibility and freedom. In traditional teaching, teachers mainly used the blackboard to present lectures, its form single, content limited and tedious, which is not conducive to attract students, especially for the inferior students. [6]MOOCs, taking the language learning scenarios into full consideration, expand the learning field from physical to virtual, and create more relaxing and harmonious atmosphere to ease students. Pre-class active self-learning and in-class guided learning are combined perfectly, which can further consolidate acquisition and improve the study effect.

Table 4: changes in environment

\begin{tabular}{c|c|c} 
& Traditional mode & Ecological mode in MOOCS \\
\hline time & 45minutes & 20minutes \\
\hline space & classroom & no limitation \\
\hline \multirow{4}{*}{ tool } & black board & Screen recording software \\
\cline { 2 - 3 } & chalk & Paper \& pen \\
\cline { 2 - 3 } & pictures & video \\
\cline { 2 - 3 } & & PPT \\
\cline { 2 - 3 } & & electronic whiteboard; \\
\cline { 2 - 3 } & & Electronic writing board
\end{tabular}

In table 4, the comparison between these two teaching modes can disclose that learning time is greatly shortened; the teaching content in traditional 45 minutes as unit can be acquired in only 20 minutes; the teaching filed becomes free of limits; teaching tools are various and advanced after MOOCs get involved.

\section{Suggestions}

Based on above analysis, the four ecological elements in MOOCs should complement and coordinate each other. Meanwhile, we should also introspect the teaching itself, concern the teaching objectives, content, methods and evaluation, and make the ecological English-major teaching mode in MOOCs practical and operable.

To establish ecological teaching objectives assisted by MOOCs and pay more attention to the compatible development among ecological elements. Conform to Teaching Syllabus for English Majors, the objectives should be completed in stages and in a sustained ecosystem by making full use of MOOC information technology.

To select ecological teaching content assisted by MOOCs. Besides language acquisition, it is more important to cultivate students' ability and foster their intellectual growth. Stressed on basic knowledge and communication skills, the content should be practical, interesting and normative, adding more social and cultural cognitive parts according to students' age, thinking pattern, knowledge structure.

To adopt ecological teaching methods assisted by MOOCs. Based on full comprehension upon textbooks and real learning situation, teaching methods should be elaborately designed, running through the knowledge lecturing, cultural influence, thinking drills, and teaching reflection. To assign proper pre-class self-learning tasks and transfer difficult and important points into questions, teachers should use MOOC technology to optimize the presentation based on teaching content, to dynamically and ecologically generate in-class teaching materials.

To design ecological teaching evaluation assisted by MOOCs. Both students and teachers should be fully considered into the evaluation, which is dynamic and two-way. Teachers can further reflect and improve their teaching while students can figure out their loopholes in study. MOOCs can help guarantee the efficiency and involvement. 


\section{Conclusion}

Compared with traditional teaching, the ecological English-major teaching has more merits and better prospect. Utilizing the dual advantages of teaching resources and information technology in MOOCs, this mode establishes a better relationship among teachers, students, English and environment, and greatly fosters English-major teaching ecosystem. However, like any other new things, there are still many obstacles for this mode to overcome, such as the confrontation with traditional teaching, its localization in English-dominating world, and deficiency of hardware and software, etc. In order to realize its long-term development, we need to continuously explore in teaching practice and improve the win-win teaching ecosystem in MOOCs, making it really practical in English-major teaching.

\section{References}

[1]Deming M, A Big-data Approach to the Study of Language Ecology[J], Computer-Assisted Foreign Language Education, 2014,155(1):3-10.

[2]Weidong, D. Establishment a One-stop English Teaching Mode with Chinese Characteristics [J].Foreign Language Teaching and Research (bimonthly), 2001, 33(5):322-327.

[3]Xiaotang, C. \& Xiao,S. Issues and challenges with English language teacher education and professional development in china[J]. Foreign Language Teaching Theory and Practice.2010 (3):1-6.

[4]Hill P. Emerging student patterns in MOOCs: A (revised) graphical view[J], e-literature, 2013(15.)

[5]Jiehui,H.\& Zhongjie,W. An Empirical Study on the MOOC-based College English Flipped Classroom Instructional Model [J]. Computer-assisted Foreign Language Education, 2014, 160(11):40-45.

[6]Zhaohui, D. An Analysis of the Current Research Foci of MOOC-Implications of the First National Symposium on Foreign Language Education of Tertiary Level in the Era of MOOCs [J]. Computer-assisted Foreign Language Education, 2015, 161(1):73-78. 